\title{
Evidence for Functional Endothelial Cell Damage in Early Diabetic Retinopathy
}

\author{
M. Porta ${ }^{1}$, C. Townsend ${ }^{1}$, G. M. Clover ${ }^{1}$, M. Nanson ${ }^{1}$, A. R. Alderson ${ }^{1}$, A. McCraw ${ }^{2}$ and E. M. Kohner ${ }^{1}$ \\ Departments of ${ }^{1}$ Medicine and ${ }^{2}$ Haematology, Hammersmith Hospital, London, UK
}

Summary. Two aspects of endothelial cell function were examined in two matched groups of male insulin-dependent diabetics, six with background retinopathy and seven without retinopathy. Leakage of fluorescein from the retinal capillaries was estimated by vitreous fluorophotometry. In addition, factors VIII/von Willebrand (VWF) and VIII-related antigen (VIII-RAG), which are synthesized by the endothelial cells, were measured, together with VIIIantihaemophilic factor (VIII-AHF). The patients without retinopathy had normal leakage of fluorescein in the macula (mean \pm SEM: $1.10 \pm 0.10 \mathrm{~g} \times$ $\left.10^{-8} / \mathrm{ml}\right)$ and the posterior vitreous $(0.45 \pm 0.11 \mathrm{~g} \times$ $10^{-8} / \mathrm{ml}$ ), and normal circulating levels of $\mathrm{vWF}$ ( $123 \%$ of a normal reference plasma $\pm 18 \%$ ), VIIIRAG $(137 \pm 14 \%)$ and VIII-AHF (112 $\pm 18 \%)$. In contrast, the patients with background retinopathy showed higher leakage of fluorescein in the macula $\left(6.34 \pm 1.74 \mathrm{~g} \times 10^{-8} / \mathrm{ml} ; p<0.01\right)$, and the posterior vitreous $\left(3.09 \pm 0.94 \mathrm{~g} \times 10^{-8} / \mathrm{ml} ; p<0.02\right)$, as well as increased levels of vWF $(177 \pm 16 \%$; $p<0.05)$. There was a trend towards increased VIIIRAG $(195 \pm 24 \% ; p<0.1)$, but not VIII-AHF (126 $\pm 13 \%$ ). Alterations of endothelial cell function thus accompany the development of retinopathy. It cannot be said from the present study whether these alterations also precede the appearance of retinopathy.

Key words: Diabetes mellitus; diabetic retinopathy, blood-retinal barrier, von Willebrand factor, factorVIII-complex.

Retinal and brain capillaries differ from others in the body by their 'tight' inter-endothelial cell junctions ('zonulae occludentes') which prevent the leakage of small molecules, such as sodium fluorescein, from the , vessel lumen into the extracellular space [1]. Appearance of fluorescein in the retina or in the vitreous after an intravenous injection of the dye, therefore, indicates breakdown of this blood-retinal barrier and is suggestive of endothelial cell damage. Fluorescein concentrations can be measured in the eye by vitreous fluorophotometry [2] and it has been reported that, in diabetes, leakage of small quantities of the dye out of the retinal vessels precedes the onset of clinical evidence of retinopathy $[2,3]$. This paper reports on observations made in two groups of insulin-dependent diabetics, one with no retinal lesions, the other with early background retinopathy. Independent evidence for generalised endothelial cell damage was sought by measuring the three activities of plasma factor-VIII-complex: von Willebrand factor (vWF), factor VIII-related antigen (VIII-RAG) and VIII-antihaemophilic factor (VIII-AHF). Of these, VWF and VIII-RAG are synthesized and stored in the endothelial cells [4] and their plasma levels are known to be increased in patients with diabetes [5,6], particularly in the presence of vascular complications $[7,8]$.

\section{Patients and Methods}

\section{Patients}

Thirteen male insulin-dependent diabetics were studied. Diabetic retinopathy was assessed by direct ophthalmoscopy, colour photographs of the fundus and fluorescein angiography. Six patients had background retinopathy and seven had none. Of the seven without visible retinopathy, two showed less than five black dots, and the remainder had no lesions when examined by fluorescein angiography. One patient in the background retinopathy group had early maculopathy and one had signs of mild hypertensive retinopathy. None had new vessels at the time of the study. 
Table 1. Clinical data of Patients

\begin{tabular}{|c|c|c|c|}
\hline & $\begin{array}{l}\text { Patients with } \\
\text { no retinopathy }\end{array}$ & $\begin{array}{l}\text { Patients with } \\
\text { background } \\
\text { retinopathy }\end{array}$ & Significance \\
\hline n. & 7 & 6 & - \\
\hline Age (years and range) & $29(19-30)$ & $36(23-46)$ & - \\
\hline Ponderal index ${ }^{\mathrm{a}}$ & $107 \pm 6$ & $103 \pm 5$ & - \\
\hline Duration of disease (years and range) & $11(3-29)$ & $11(5-21)$ & - \\
\hline Insulin dose (U/day) & $44 \pm 7$ & $46 \pm 5$ & - \\
\hline $\mathrm{HbA}_{1}$ ( $\%$ of total $\mathrm{HbA}$ and range) & $11.4(8.8-14.4)$ & $10.6(5.2-19.2)$ & $-^{\mathrm{c}}$ \\
\hline Plasma glucose (mmol/l and range) ${ }^{b}$ & $16.1(4.8-22.7)$ & $12.4(2.1-18.7)$ & $-^{\mathrm{c}}$ \\
\hline Time between breakfast and venipuncture ( $\mathrm{min}$ and range) & $89(30-135)$ & $162(90-210)$ & $-^{c}$ \\
\hline Urea $(\mathrm{mmol} / \mathrm{l})$ & $5.6 \pm 0.7$ & $6.0 \pm 0.5$ & - \\
\hline Creatinine ( $\mu \mathrm{mol} / 1$ and range) & $89(81-111)$ & $92(63-104)$ & $-c$ \\
\hline Total serum cholesterol $(\mathrm{mmol} / \mathrm{l})$ & $4.5 \pm 0.2$ & $6.2 \pm 0.2$ & $p<0.001$ \\
\hline
\end{tabular}

a Percent of desirable body weight, according to the middle of the weight range for subjects of medium frame [21]

b Non-fasting values measured at the beginning of the study

c Wilcoxon's rank sum test

The two groups of patients had similar age, duration of disease, ponderal index, daily insulin dose, haemoglobin $A_{1}\left(\mathrm{HbA}_{1}\right)$ and plasma glucose levels at the beginning of the study (Table 1). One patient was on $\alpha$-methyldopa and chlorthalidone, and one on propranolol for the treatment of mild hypertension, both belonging to the group with retinopathy. None of the others was on any medication apart from insulin. None of the patients had clinical signs of neuropathy (as evaluated by knee and ankle reflexes, vibratory sensation, postural hypotension, impotence), nor of large vessel disease (as assessed by peripheral pulses, ECG, history of claudication, angina or myocardial infarction).

Normal values for vitreous fluorophotometry were measured in a group of seven healthy male volunteers, mean age 29 years (range 21-38 years), ponderal index $106 \pm 10 \%$ (mean \pm SEM). Normal values for factor-VIII-complex were measured in 15 healthy male subjects, mean age 47 years (range 20-64 years), ponderal index $111 \pm 10 \%$.

\section{Experimental Protocol}

The procedure had been approved by the Hospital Ethical Committee and informed consent was obtained from the patients, in accordance with the Helsinki Declaration of 1975 . Non-fasting blood samples were taken at $09.00-09.30 \mathrm{~h}$ for the measurements of vWF, VIII-RAG, VIII-AHF, plasma glucose, $\mathrm{HbA}_{1}$, total serum cholesterol, urea and creatinine (Table 1).

Baseline photometric readings were taken at the macula and the posterior vitreous of the right eye. These were followed by ophthalmoscopic examination and colour photography of the fundus. Fluorescein angiograms were subsequently obtained, following the injection of $1000 \mathrm{mg}$ of fluorescein $(5 \mathrm{ml}$ of a $20 \%$ solution). One hour after the injection the concentrations of fluorescein leaked from the retinal vessels into the macula and the posterior vitreous were measured by fluorophotometry.

Blood Tests. Nine $\mathrm{ml}$ of blood for the assays of factor-VIII-complex were collected without stasis from an antecubital vein, using a 19 gauge $(1.1 \mathrm{~mm})$ butterfly needle, into a plastic syringe and immediately mixed with $1 \mathrm{ml}$ of $120 \mathrm{mmol} / 1$ trisodium citrate. The samples for biochemical assays were taken with a second syringe. The tests for VWF, VIII-RAG and VIII-AHF were run in the same assays. vWF was measured by a modification of the method of
Weiss et al. [9] (intra-assay variation $=9.4 \%$ ), factor VIII-RAG by immunoelectrophoresis using Laurell's technique [10] (intraassay variation $=5.2 \%$ ), and factor VIII-AHF by the one-stage assay [11] (intra-assay variation $=8.1 \%$ ). The values of the three factors are expressed as percentages of the activity measured in a standard pooled plasma obtained from 24 healthy donors. Plasma glucose was measured by the glucose-oxidase technique [12], and $\mathrm{HbA}_{1}$ by commercial kits (Bio-Rad) (normal range $=5.0-9.6 \%$; intra-assay variation $=5.9 \%$, inter-assay variation $=14.5 \%$ ). Total serum cholesterol was measured by Autoanalyzer (Technicon 2) (normal range $=4.0-6.5 \mathrm{mmol} / \mathrm{l}$ ), urea and creatinine were measured by an IL 915 Analyzer (normal ranges $=2.5-6.5 \mathrm{mmol} / 1$ and $55-125 \mu \mathrm{mol} / 1$, respectively).

Vitreous Fluorophotometry. The technical details of vitreous fluorophotometry have been fully described in a separate paper [13]. This technique is based on the fact that the intensity of green light (wave length $=525 \mathrm{~nm}$ ) emitted when fluorescein is excited by blue light (wave length $=490 \mathrm{~nm}$ ) is a function of the concentration of the dye [2]. The main feature of the equipment used is a $700-\mu \mathrm{m}$ diameter light sensitive probe (Gamma Scientific, S. Diego, California) placed in the focal plane of the ocular of a slit-lamp (Zeiss, Type 100/16). White light obtained from a cold light source (Supa-Lite, Keeler, England), connected to the slitlamp via a fibre-optic, is passed through a blue filter (Baird Atomic No. 4) and projected into the eye of the patient as a beam of $1.5 \times 3.0 \mathrm{~mm}$ in the focal plane. This is focused first on the macular area of the retina, and then withdrawn, until it is clear of reflected light from the retina, into the posterior vitreous. In these situations, readings are taken of the intensity of fluorescent light emitted. The light sampled by the probe is passed through a green filter (Baird Atomic No.5) to a photomultiplier tube (Gamma Scientific, 2020-1 Sil) and thence to the digital read-out of a photometer (Gamma Scientific 2400). For each patient the mean of two consecutive readings was calculated. The sensitivity of the apparatus was such that concentrations of $10^{-9} \mathrm{~g} / \mathrm{ml}$ fluorescein could be detected. On the day of each experiment a best-line fit was calculated of the intensities of green light emitted in the same system by a series of six aqueous solutions of sodium fluorescein $(\mathrm{pH} 7.4)$ of known concentrations $\left(1 \times 10^{-9}, 5 \times 10^{-9}\right.$, $1 \times 10^{-8}, 5 \times 10^{-8}, 1 \times 10^{-7}$ and $\left.5 \times 10^{-7} \mathrm{~g} / \mathrm{ml}\right)$. This line was used to estimate in $\mathrm{g} \times 10^{-8} / \mathrm{ml}$ the concentrations of fluorescein leaked into the macula and the posterior vitreous. Minimal but 


$$
\left.\begin{array}{cc} 
& 10 \\
\bar{E} & \\
\underset{\infty}{\infty} & 5 \\
\times & \\
\sigma &
\end{array}\right]
$$
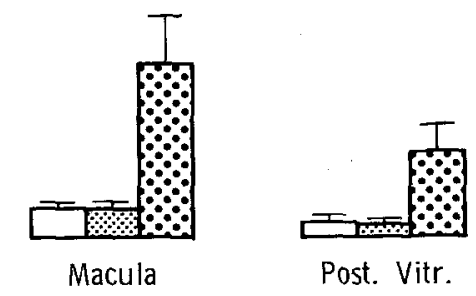

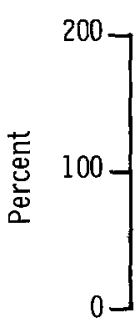
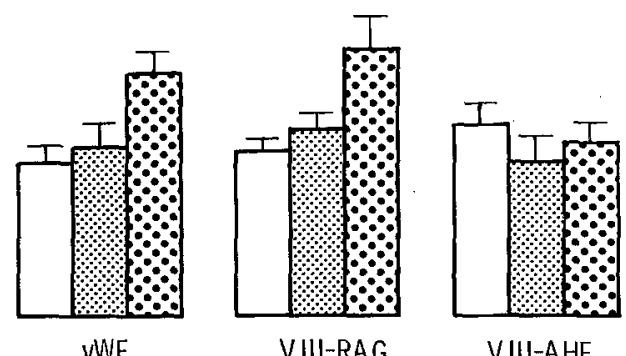

VIII-AHF

consistent levels of light intensity were always detected in the eye before injecting fluorescein and were probably an artifact due to autofluorescence of the lens [14] and reflection and detection of blue exciting light. Consequently, baseline readings were taken before injecting the dye and the values subtracted from those obtained $1 \mathrm{~h}$ later.

Calculations. Statistical analysis was performed by Student's $\mathbf{t}$ test or, when the data were not normally distributed, by Wilcoxon's rank sum test. The results are expressed as mean \pm SEM.

\section{Results}

Figure 1 shows that the diabetic patients with background retinopathy had higher leakage of fluorescein than the patients without retinopathy, both into the macula $\left(6.34 \pm 1.74\right.$ and $1.10 \pm 0.10 \mathrm{~g} \times 10^{-8} / \mathrm{ml}$, respectively; $p<0.01$ ), and into the posterior vitreous $\left(3.09 \pm 0.94\right.$ and $0.45 \pm 0.11 \mathrm{~g} \times 10^{-8} / \mathrm{ml}$, respectively; $p<0.02$ ). The values of the diabetics without retinopathy were similar to those measured in normal controls in the macula $(1.13 \pm 0.09 \mathrm{~g} \times$ $\left.10^{-8} / \mathrm{ml}\right)$ and in the posterior vitreous $(0.55 \pm 0.19 \mathrm{~g}$ $\times 10^{-8} / \mathrm{ml}$ ). vWF levels were higher in the diabetics with background retinopathy $(177 \pm 16 \%)$ than in the patients without retinopathy $(123 \pm 18 \% ; p<$ $0.05)$, and the normal controls $(112 \pm 13 \% ; p<$ $0.005)$. A trend to increased values was found for factor VIII-RAG in background retinopathy (195 士 $24 \%$ ) when compared with patients without retinopathy $(137 \pm 14 \% ; p<0.1)$, and normal controls $(118 \pm 11 \% ; p<0.025)$. The levels of factor VIII-AHF were similar in the diabetics with $(126 \pm$

Fig. 1. Capillary permeability and factor-VIII-complex in diabetic retinopathy. The upper histograms show the concentrations of fluorescein (mean \pm SEM) leaked from the retinal capillaries into the macula (top left) and the posterior vitreous (post vitr.) (top right) of normal subjects and diabetic patients with and without retinopathy. The lower histograms indicate the plasma levels of von Willebrand factor (vWF), factor VIII-related antigen (VIIIRAG) and VIII-antihaemophilic factor (VIII-AHF) (mean \pm SEM) measured in the same groups.

$\square=$ Normal controls; $\$$ = patients without retinopathy; = patients with background retinopathy

$13 \%)$ and without retinopathy $(112 \pm 18 \%)$ and in the controls $(138 \pm 16 \%)$. The values of factor VIIIRAG correlated better with those of vWF ( $\mathrm{r}=0.83$, $p<0.001)$ than with those of VIII-AHF $(\mathbf{r}=0.58$, $p<0.05$ ). Total serum cholesterol was higher in the patients with retinopathy $(6.2 \pm 0.2 \mathrm{mmol} / \mathrm{l})$ than in those without $(4.5 \pm 0.2 \mathrm{mmol} / \mathrm{l} ; p<0.001)$, but was within the normal range in both groups (Table 1 ).

\section{Discussion}

This work shows that anatomical evidence of diabetic retinopathy is accompanied by functional impairment of the endothelial cells, involving alterations of molecular transport through the vessel wall and the metabolism of vWF.

Previous studies of vitreous fluorophotometry in diabetes have reported breakdown of the blood-retinal barrier even in patients without retinopathy, in contrast with virtually no leakage of fluorescein from the capillaries of normal controls $[2,3]$. These findings were not reproduced in the present work, in which fluorescein concentrations were measured not only in the posterior vitreous but also in the macular area of the retina. Minimal though consistent leakage of the dye was always observed in healthy volunteers and, to the same extent, in diabetics without ophthalmoscopic signs of retinopathy, while gross leakage of fluorescein was found only in patients with background retinopathy (Fig. 1). These results suggest that small quantities of fluorescein may cross the capillary wall even in health and that breakdown of 
the blood-retinal barrier accompanies but does not precede the clinical onset of diabetic retinopathy.

Vitreous fluorophotometry is a delicate experimental procedure still under assessment in various laboratories, and major differences in the technical approach or in the choice of the patients may account for the difference between these data and those in the literature. The problems encountered in this laboratory in developing the technique, and the solutions proposed, form the object of a separate paper [13] and stress the need for carefully standardizing the procedure in the various centres.

Further evidence in this work supports the hypothesis that the endothelial function is still intact in some patients without retinopathy. Endothelial cells synthesize and store vWF [4], a glycoprotein which facilitates the adhesion of blood platelets to subendothelial structures exposed in the case of vessel wall damage [15]. vWF circulates in connection with factor VIII-AHF, which is not produced by the endothelial cells, forming the so-called factor-VIIIcomplex [4]. In this study, increased levels of vWF were found only in the patients with retinopathy but not in those without retinopathy, which is in agreement with some of the previous reports in the literature $[7,8]$ although other workers have found high levels of vWF also in patients without evident vascular complications [5, 6]. Retinopathy is thought to be the most easily detectable early sign of generalized deterioration of the body microvasculature in diabetic microangiopathy and it has been suggested that vWF is elevated as a result of release from damaged endothelial cells [7]. This may strengthen platelet adhesion to vascular subendothelium, and could result in platelet activation and release of factors increasing the permeability of the vessel wall [16]. The values of factor VIII-RAG correlated with those of $\mathrm{vWF}$, as commercial antisera react with this subunit of factor-VIII-complex [4]. Factor VIII-AHF was within normal limits in both groups of diabetics, in accordance with previous reports of its dissociation from vWF in diabetic retinopathy [8].

Of the other parameters studied, only total serum cholesterol was significantly different between the two groups of patients, though still within the normal range (Table 1 ). This observation supports previous reports from this Unit [17] but its importance in endothelial cell function is not known. A positive correlation between total serum cholesterol and the degree of metabolic control has recently been reported in young insulin-dependent diabetics [18]. However, the patients of this study had similar levels of $\mathrm{HbA}_{1}$ and postprandial plasma glucose (Table 1 ), indicating that diabetic control is not the only factor involved in the regulation of cholesterol levels.
Changes in metabolic control were also reported to be important in altering the blood-retinal barrier function in diabetic rats [19] and possibly in man [20]. However, the results of this work suggest that control may not be a major determinant of capillary permeability, once retinopathy has developed.

Acknowledgements. This work was supported by the British Heart Foundation (Grant BHF 821), the Royal National Institute for the Blind, the British Diabetic Association and Servier Products.

\section{References}

1. Shakib M, Cunha-Vaz JG (1966) Studies on the permeability of the blood-retinal barrier. 4. Junctional complexes of the retinal vessels and their role in the permeability of the bloodretinal barrier. Exp Eye Res 5: 229-234

2. Cunha-Vaz JG, Abreu JF, Campos AJ, Figo GM (1975) Early breakdown of the blood-retinal barrier in diabetes. Br J Ophthalmol 59: 649-656

3. Waltman SR, Oestrick C, Krupin T, Hanish S, Ratzan S, Santiago J, Kilo C (1978) Quantitative vitreous fluorophotometry: a sensitive technique for measuring early breakdown of the blood-retinal barrier in young diabetic patients. Diabetes 27: 85-87

4. Bloom AL (1979) The biosynthesis of factor VIII. Clin Haematol 8: 53-77

5. Lufkin EG, Fass DN, O'Fallon WM, Bowie EJW (1979) Increased von Willebrand factor in diabetes mellitus. Metabolism 28: 63-66

6. Gensini GF, Abbate R, Favilla S, Neri Serneri GG (1979) Changes of platelet function and blood clotting in diabetes mellitus. Thromb Haemostas 42: 983-993

7. Coller BS, Frank RN, Milton RC, Gralnick HR (1978) Plasma co-factors of platelet function: correlation with diabetic retinopathy and hacmoglobins $A_{1 a-c}$. Studies in diabetic patients and normal persons. Ann Intern Med 88: 311-316

8. Bensoussan D, Levy-Toledano J, Passa P, Caen J, Canivet J (1975) Platelet hyperaggregation and increased plasma levels of von Willebrand factor in diabetics with retinopathy. Diabetologia 11: 307-312

9. Weiss HJ, Hoyer LW, Rickles FR, Varma A, Rogers J (1973) Quantitative assay of a plasma factor deficient in von Willebrand's disease that is necessary for platelet aggregation. Relationship to factor VIII procoagulant activity and antigen content. J Clin Invest 52: 2708-2716

10. Laurell CB (1972) Electroimmunoassay. Scand J Clin Lab Invest 29 (Suppl 124): 21-37

11. Hardisty RM, McPherson JC (1962) A one-stage factor VIII (antihaemophilic globulin) assay and its use on venous and capillary plasma. Thromb Diath Haemorrh 7: 215-229

12. Robin M, Seifer A (1965) Determination of glucose in biologic fluids with an automated enzymatic procedure. Clin Chem 11: $840-45$

13. Alderson AR, Nanson EM, Townsend C, Porta M, Arnold J, Clover GM, Kohner EM (in press) Vitreous fluorophotometry: equipment and methods. Clin Phys Physiol Meas

14. Francois J, Rabaey M, Recoules N (1961) A fluorescent substance of low molecular weight in the lens of primates. Arch Ophthalmol 65: 118-126

15. Tschopp BT, Weiss HJ, Baumgartner HR (1974) Decreased adhesion of platelets to subendothelium in von Willebrand's disease. $\mathrm{J} \mathrm{Lab} \mathrm{Clin} \mathrm{Med} \mathrm{83:} \mathrm{296-300}$ 
16. Nachman RL, Weksler B, Ferris B (1972) Characterization of human platelet vascular permeability-enhancing activity. J Clin Invest 51: 549-556

17. Kissebah AH, Sidding YK, Kohner EM, Lowy C, Lewis B, Fraser TR (1975) Plasma-lipids and glucose/insulin relationship in non-insulin-requiring diabetics with and without retinopathy. Lancet 2: 1104-1107

18. Sosenko JM, Breslow JL, Miettinen OS, Gabbay KH (1980) Hyperglycaemia and plasma lipid levels. A prospective study of young insulin-dependent diabetic patients. N Engl J Med 302: $650-654$

19. Jones CW, Cunha-Vaz JG, Zweig KO, Stein M (1979) Kinetic vitreous fluorophotometry in experimental diabetes. Arch Ophthalmol 97: 1941-1943

20. Cunha-Vaz JG, Fonseca JR, Abreu JF, Ruas MA (1979)
Detection of early retinal changes in diabetes by vitreous fluorophotometry. Diabetes 28: 16-19

21. Diem K, Lentner C (cds) (1970) Desirable body weights of adults. In: Scientific tables. TR Geigy, Basel, p 712

Received: 12 August 1980

and in revised form: 11 December 1980

\section{Dr. M. Porta}

Department of Medicine

Hammersmith Hospital

Du Cane Road

London W12 OHS

England 